\title{
ILCEA
}

Revue de l'Institut des langues et cultures

d'Europe, Amérique, Afrique, Asie et Australie

18 | 2013

Les frontières dans le monde hispanique

\section{Creacion de una frontera literaria: perspectivismo y contradicción en las Cartas Marruecas de José Cadalso}

Creation of a Literary Frontier: Perspective and Contradiction in Moroccan

Letters, by José Cadalso

Francisco Javier Rodríguez Barranco

\section{OpenEdition}

\section{Journals}

Edición electrónica

URL: http://journals.openedition.org/ilcea/2084

DOI: $10.4000 /$ ilcea.2084

ISSN: 2101-0609

Editor

UGA Éditions/Université Grenoble Alpes

Edición impresa

ISBN: 978-2-84310-251-6

ISSN: 1639-6073

\section{Referencia electrónica}

Francisco Javier Rodríguez Barranco, « Creacion de una frontera literaria: perspectivismo y

contradicción en las Cartas Marruecas de José Cadalso », ILCEA [En línea], 18 | 2013, Publicado el 11

julio 2013, consultado el 08 enero 2020. URL : http://journals.openedition.org/ilcea/2084 ; DOI

10.4000/ilcea.2084

Este documento fue generado automáticamente el 8 enero 2020.

(C) ILCEA 


\title{
Creacion de una frontera literaria: perspectivismo y contradicción en las Cartas Marruecas de José Cadalso
}

\author{
Creation of a Literary Frontier: Perspective and Contradiction in Moroccan \\ Letters, by José Cadalso
}

Francisco Javier Rodríguez Barranco

\section{Contradicciones}

1 Hijo de su tiempo, dentro de un siglo que busca su propia identidad, encajonado entre los epígonos del barroco y los arrebatos del romanticismo, a caballo entre el absolutismo y las grandes revoluciones de la modernidad (independencia de los Estados Unidos de América, Revolución Francesa, emancipación de las colonias españolas), que permitieron a grandes extensiones del planeta evolucionar desde el poder omnímodo del monarca hasta el parlamentarismo de la República, miembro, pues de una centuria marcada por el despotismo ilustrado, lo cual encierra en sí mismo una contradicción flagrante, José Cadalso (1741-1782) fue una persona intrínsecamente contradictoria, lo que nos permite justificar el título de este ensayo y de este epígrafe, y probablemente la mayor de las contradicciones fue su empeño en mantenerse como un militar ilustrado, porque si bien la lanza nunca empañó la pluma, en opinión de don Quijote, como es sobradamente conocido, lo cierto es que las Fuerzas Armadas españolas, con algunas excepciones, por supuesto, no se han caracterizado precisamente por su amor al saber. De manera que, Cadalso escribió un bien conocido manual burlesco en 1770 Los eruditos a la violeta, publicado en 1772, fecha en que redactó El buen militar a la violeta, que dejó inédito, como si entre la erudición y la milicia pudiera haber otro punto de conexión que la frivolidad dieciochesca, incluso dentro de unas coordenadas paródicas y satíricas. En opinión de Alborg, sobre la estima que el escritor gaditano podía inspirar entre sus jefes: «un militar que se permitía escribir versos de amor o hacer críticas en prosa de las normas establecidas, debía de resultar tan desconcertante como incómodo» ${ }^{1}$. 
2 Pero es en los pequeños detalles cotidianos o profesionales donde Cadalso ofrece su perfil más contradictorio, como en lo que afecta a la moda, según leemos en las Cartas marruecas: «Éste [el químico] se ríe del soldado que trabaja mucho sobre que la vuelta de la casaca tenga tres pulgadas de ancho, y no tres y media» (Carta XV); cuando Cadalso era famoso por sus gustos exquisitos, sobre todo en lo referente a su indumentaria. No es excepcional que en sus obras apunte alguna autocrítica benévola: el mismísimo Nuño, que es la austeridad personificada, admite a Gazel que «Aquí donde me ves, yo he tenido algunas temporadas de petimetre» (Carta LXIV). O cuando se muestra poco proclive a la movilidad social, pues aunque sus puntos de vistas sean progresistas: «la demasiada prudencia de los viejos hace imposible las cosas más fáciles» (Carta LXXIX), según piensa Nuño, los personajes cadalsianos defienden la estructura social vigente, incluso desde el mismo momento de la educación, puesto que establecidos los tres estratos esenciales:

en Europa la educación de la juventud debe mirarse como objeto de la primera importancia. El que nace en la ínfima clase de las tres, y que ha de pasar su vida en ella, no necesita estudios, sino saber el oficio de su padre en los términos en que se lo ve ejercer. El de la segunda ya necesita otra educación para desempeñar los empleos que ha de ocupar con el tiempo. Los de la primera se ven precisados a esto mismo con más fuerte obligación (Carta VII),

opina Gazel desde el inicio de las Cartas: opiniones de un marroquí, de un joven marroquí para mayor abundamiento, sobre la educación de la juventud europea, que transcribe c por b la ideología social de Cadalso, porque es mediante el entramado de la mirada extranjera como el escritor español apuntala sus postulados esenciales y adquiere cierta distancia elevada sobre la circunstancia para reírse de sí mismo en ocasiones, o para elaborar las contradicciones intrínsecas del texto.

\section{Perspectivismo}

El artificio elegido, en efecto, permite al autor un interesantísimo juego de perspectivas, puesto que es obvio que personajes con orígenes nacionales diferentes, a uno y otro lado del Estrecho de Gibraltar, con culturas, lenguas y religiones diferentes y en situaciones vitales diferentes, sobre todo en cuando a la edad o el estado de evolución personal, son las coordenadas idóneas para ofrecer las diferentes caras de una cuestión. Un juego de perspectivas, que posibilita el que Nuño y Gazel debatan sobre la mejor conducta a seguir por una persona de talento, puesto que para el segundo:

El mérito oculto en el mundo es despreciado, y si se manifiesta, atrae contra sí la envidia y sus secuaces. ¿Qué ha de hacer, pues, el hombre que lo tiene? Retirarse a donde pueda ser útil sin peligro propio. (Carta LXIX)

Mientras que el austero español lamenta la pérdida para la república de los virtuosos mediante una pareja de preguntas retóricas en respuesta a la anterior carta de Gazel:

¿No te parece lastimosa para el estado la pérdida de unos hombres de talento y mérito que se apartan de las carreras útiles de la república? ¿No crees que todo individuo está obligado a contribuir al bien de su patria con todo esmero? (Carta LXX)

Para que no quepa ninguna duda, desbarata Nuño la preceptiva básica de una pregunta retórica respondiendo él mismo dentro de la misma carta que «No basta ser bueno para sí y para otros pocos; es preciso serlo o procurar serlo para el total de la nación»; puesto que de otro modo, «aunque sea hombre bueno, será mal ciudadano». Y no vamos a emitir nuestra propia opinión, que probablemente sea intrascendente, sino tan sólo enfatizar ese 
juego de perspectivas, sobre el que vuelve Gazel, puesto que no satisfecho con la opinión del español, escribe a su maestro Ben-Beley que «le dan al hombre gana de retirarse a lo más recóndito de nuestra África, huir de sus semejantes y escoger la morada de los desiertos o montes entre fieras y brutos» (Carta LXXXI), si bien referido al hombre en general, y no exclusivamente al de talento.

Sin embargo, Nuño no es del todo coherente consigo mismo, pues si a Gazel le afea el retiro público de los hombres de talento, en un momento de escepticismo sobre la humanidad manifiesta a Ben-Beley que:

Dichoso tú, que separado del bullicio del mundo empleas tu tiempo en inocentes ocupaciones y no tienes que sufrir tanto delirio, vicio y flaqueza como abunda entre los hombres, sin que apenas pueda el sabio distinguir cuál es el vicio y cuál es virtud entre los varios móviles que los agitan. (Carta XXII)

7 La crítica española que con mayor profundidad ha abordado el estudio de las Cartas marruecas destaca la condición de «sátira oblicua» de esta obra, es decir, una denuncia de vicios «no ejercida directamente, sino conseguida de rechazo, al ser provocado el choque de unos valores, de un sistema de vida que consideramos normal, con la mirada de unos seres ajenos a ese sistema y capaces, por tanto, de verlo y enjuiciarlo con objetividad", como señala Baquero Goyanes ${ }^{2}$. Juan Luis Alborg, por su lado, diferencia entre el método científico de Feijoo, Jovellanos y Moratín, para los cuales todo problema tiene su solución, de la actitud de Cadalso, quien «duda frecuentemente, a través del debate de sus personajes, y más que soluciones nos da puntos de vista» ${ }^{3}$. Por su parte, GlendinningDupuis subraya:

Mientras que Feijoo, Jovellanos y Leandro Fernández de Moratín creen que todos los problemas que plantean tienen solución, Cadalso es más escéptico y sus personajes reflejan sus dudas acerca de la posibilidad de saber cualquier cosa a ciencia cierta ${ }^{4}$.

El perspectivismo se traslada también al nivel de veracidad que ha de tener la Historia en los manuales, algo que para Nuño puede ser relativo, puesto que no considera prudente para gente poco preparada una rigurosa certeza en los acontecimientos del siglo en curso y el anterior, sino tan sólo de lo sucedido, al menos con doscientos años de antigüedad. Esta diferenciación permitiría tres tipos de manuales: uno para el pueblo, sin entrar en demasiados detalles en cuanto a la contemporaneidad, otro más auténtico, pero no demasiado, para gente mediana y, por fin, otro cargado de reflexiones políticas y morales para uso de los príncipes. En cambio Gazel opina que

no me parece mal esta treta en lo político y creo que algunos historiados españoles lo han ejecutado, a saber: Garibay con la primera mira, Mariana con la segunda, y Solís con la tercera. Pero yo no soy político ni aspiro a serlo; deseo sólo ser filósofo, y en este ánimo digo que la verdad sola es digna de llenar el tiempo y ocupar la atención de todos los hombres, aunque singularmente a los que mandan a otros (Carta L),

por lo que la cuestión queda planteada, pero no resuelta: dos pensamientos diferentes, dos posibilidades distintas, de las que Cadalso quiere dejar constancia para conocimiento del lector, sin que descienda a aleccionarle con sus propias opiniones, lo que degradaría el volumen del perspectivismo en una sucesión de opiniones planas, las opiniones del autor, más o menos acertadas, pero planas, sin la riqueza de posibilidades de un contraste de enfoques.

Algo más complejo es la visión triple sobre una de las cuestiones esenciales del ser humano, en general, como es la eternidad a través de la fama póstuma, algo que para 
Platón constituye el segundo de los tres niveles para alcanzar la inmortalidad, situada entre la perpetuación por el cromosoma en el primer nivel y la contemplación de la esencia en el más excelso. Es así como el filósofo ateniense enfoca la cuestión en $E l$ banquete o Del amor:

[...] lo muy poseídos que están los hombres de crearse un nombre y de adquirir una gloria inmortal en la posteridad, y que este deseo, más aún que el amor paternal, es lo que los lleva a afrontar todos los peligros, sacrificar su fortuna, soportar todas las fatigas y hasta perder la vida 5 .

En las Cartas marruecas, de Cadalso, Gazel no comprende el interés de Nuño por ese tema, ni la propia cuestión de la fama, en sí:

Toda la noche pasada me estuvo hablando mi amigo Nuño de una cosa llamada fama póstuma. Este es un fantasma que ha alborotado muchas provincias y quitado el sueño a muchos, hasta secarles el cerebro y hacerles perder el juicio. Alguna dificultad me costó entender lo que era, pero lo que aún no puedo comprender es que haya hombres que apetezcan la tal fama. Cosa que no he de gozar, no sé por qué he de apetecerla. (Carta XXVII)

Opinión compartida por Ben-Beley, aunque sabiamente matizada en su respuesta a Gazel:

He leído muchas veces la relación que me haces de esas especies de locuras que llaman deseo de la fama póstuma. Veo lo que me dices del exceso de amor propio, de donde nace esa necedad de querer un hombre sobrevivirse a sí mismo. Creo, como tú, que la fama póstuma de nada sirve al muerto, pero puede servir a los vivos con el estímulo del ejemplo que deja el que ha fallecido. Tal vez éste es el motivo político del aplauso que logra. (Carta XXVIII)

11 Y dentro de esa misma carta menciona a Tarif, a Aquiles, a Ciro y a Alejandro, demostrando así un gran conocimiento de la Historia de su pueblo, tanto como de la mitología griega y la Historia Antigua. Pero más adelante, ya hacia el final del libro, BenBeley vuelve sobre esta cuestión con notable arrepentimiento respecto a sus primeras afirmaciones, lo que me parece un ejemplo extraordinario del volumen como de prisma que tiene la obra de Cadalso, a la par que asistimos a un episodio de disconformidad con uno mismo, próxima a la contradicción intratextual:

No enseñes a tus amigos la carta que te escribí contra esa cosa que llaman fama póstuma. Aunque ésta es una de las mayores locuras del hombre, es preciso dejarla reinar como otras muchas. Pretender reducir el género humano a sólo lo que es naturalmente bueno, es pretender que todos los hombres sean filósofos, y esto es imposible. Después de escribirte meses ha sobre este asunto, he considerado que el tal deseo es una de las pocas cosas que pueden consolar al hombre de mérito desgraciado. (Carta LXXXIV)

12 De donde podemos arriesgar un referente personal en la vida de Cadalso, puesto que finaliza las Cartas marruecas en 1774, siendo así que poco antes, dentro del plazo natural de los doce meses del año de 1771, le sucedieron todos estos infortunios: la censura no autoriza el estreno de su obra Soraya o los circasianos; el 22 de abril muere María Ignacia Ibáñez, de la que estaba enamorado; cae enfermo, se siente abandonado por sus amigos; y rompe su amistad con Joaquín Oquendo, a quien había conocido tan sólo dos años antes, en 1769, y que era protegido del conde de Aranda. De manera que, según nuestra arriesgada conjetura, sería el propio Cadalso uno de los hombres de mérito que se esconden bajo la genérica mención de Ben-Beley.

Por fin, en lo que al tercer corresponsal y la fama póstuma se refiere, ya hemos visto que Gazel alude a una extensa perorata del español, no explicitada en las Cartas, para dar inicio a sus reflexiones sobre la cuestión, pero sí que constan las opiniones de Nuño con 
respecto a uno de los grandes héroes nacionales, en una extensa carta, concretamente la IX, donde se hace una exhaustiva mención de veinte acciones heroicas dirigidas por el extremeño en la derrota del imperio azteca, de la que sólo citaré un fragmento de la número 4, que tiene que ver con las victorias logradas, a pesar de la desproporción en el número de combatientes en uno y otro bando:

Este es el caso de los pocos españoles contra innumerables americanos, y esta misma proporción se ha de tener presente en la relación de todas las batallas que el gran Cortés ganó en aquella conquista.

Y más explícita, aunque mediante la voz indirecta de Gazel, es la opinión de Nuño: Pero mi amigo Nuño dice que ya es demasiado el número de gentes que en España siguen el sistema de la indiferencia sobre esta especie de fama. O sea el carácter del siglo, o espíritu verdadero de filosofía; o sea consecuencia de la religión, que mira como vanas, transitorias y frívolas las glorias del mundo, lo cierto es que en la realidad es excesivo el número de los que miran el último día de su vida como el último de su existencia. (Carta LXXXV)

Lo que sin duda mortifica a Nuño y por ende a Cadalso. Pero lo que más importante me parece en este punto es constatar cómo se establece esta triple perspectiva de opiniones, construida sobre la ficción de unas cartas extranjeras que viajan a uno y otro lado del Estrecho de Gibraltar, de la misma manera que un marroquí, Gazel, lo cruzó hacia el norte en su viaje a España y lo cruzará hacia el sur cuando termine la obra de Cadalso, que eligió la técnica del género epistolar porque «hace su lectura más cómoda, su distribución más fácil, y su estilo más ameno, como también a lo extraño del carácter de los supuestos autores», según declara en la «Introducción» de las Cartas marruecas. Por otro lado, el propio género epistolar es intrínsecamente perspectivesco, puesto que el "género epistolar permite la presentación alternada de varias voces, sus entrecruzamientos, sus choques y fusiones», en opinión de Baquero Goyanes ${ }^{6}$, quien no duda en reforzar su propia afirmación: «es preciso advertir que, de todos los procedimientos narrativos, es el epistolar el que mejor puede expresar una intención perspectivística» ${ }^{7}$. Si unimos las posibilidades de las cartas como soporte de varias perspectivas con las culturas diferentes a que pertenecen los corresponsales, nos encontramos con la esencia de la obra de Cadalso, pues los redactores de las epístolas en las Cartas marruecas son supuestos autores de distintas nacionalidades, como no podía ser de otra manera cuando lo que se pretende es la creación de una frontera literaria.

Perspectivismo con cierta dosis de contradicción detectamos en dos pasajes del texto de Cadalso, pues mientras Nuño afirma en la Carta XL que «No es el género humano tan malo como otros le suelen pintar, y como efectivamente le hallan los que no son buenos»; poco después en la XLIV el mismo personaje mantiene que «Confírmate en la idea del hombre es tan malvada que, para valerme de tu propia expresión, suele viciar hasta las virtudes mismas»; siendo así que ambas cartas están dirigidas al mismo corresponsal: Gazel. Algo más conciliador se muestra el español en la epístola a Ben-Beley, pues ha «visto en una de las cartas que Gazel te escribe un retrato horroroso del siglo actual», pero:

Otro efecto le hubiera causado una relación de la suavidad de costumbres, humanidad en la guerra, noble uso de las victorias, blandura en los gobiernos; los adelantamientos en las matemáticas y física; el mutuo comercio de talentos por medio de las traducciones que se hacen en todas las lenguas de cualquiera obra que sobresale en alguna de ellas. Cuando todas estas ventajas no sean efectivas como lo parecen, pueden a lo menos hacer equilibrio con la enumeración de desdichas que hace Gazel. (Ambas citas en la Carta XLVIII.) 
Nuño alcanza por fin ahí un término medio entre lo rotundamente bueno y lo rotundamente malo entre las anteriores Cartas XL y XLIV y nos brinda un magnífico ejemplo del perspectivismo en las opiniones del joven marroquí y el cauto castellano, referido en esta ocasión a un tema tan esencial como las virtudes, donde podemos afirmar con Glendinning-Dupuis que en la obra de Cadalso

[...] se vislumbra algo así como una doctrina de hombría de bien relacionada con el estoicismo, a la que todos los personajes principales se atienen, y que es la única actitud adecuada en un mundo regido por una fortuna más o menos ciega y por las pasiones de la mayoría de los hombres ${ }^{8}$,

todo ello dentro de un libro que dificulta cualquier interpretación ideológica coherente, por la falta de ordenación cronológica y por la propia exposición de las ideas, que muchas veces parecen conjeturas más que opiniones definitivas: encadenamientos de puntos de vista, más que un manifiesto ético, inserto además en una atmósfera de contradicciones.

Muy curioso es el caso de Ben-Beley, el más distante de los corresponsales respecto de los hechos relatados en las epístolas, como podemos comprobar en carta de éste a Nuño, a quien agradece la dirección espiritual del joven Gazel:

Pero aun así, dime, Nuño, ¿son verdaderas muchas de las noticias que me envía sobre las costumbres y usos de tus paisanos? Suspendo el juicio hasta ver tu respuesta. Algunas cosas me escribe incompatibles entre sí. Me temo que su juventud le engañe en algunas ocasiones y me represente las cosas no como son, sino cuales se le representaron. (Carta XX)

Lo cual introduce la apasionante posibilidad que desbordaría con creces las intenciones de este ensayo, de analizar las Cartas marruecas a la luz del Quijote, donde también existe una distancia importante entre lo que las cosas son y cómo se le representan al desventurado caballero. En lo que estrictamente hace a nuestro objetivo, quiero destacar la variedad de criterios que se establecen: el juvenil y extranjero de Gazel, el intelectual hispano de Nuño y el filosófico oriental de Ben-Beley y cómo eso se explicita con precisión en el texto de Cadalso.

19 El análisis de la técnica perspectivística se dirige también a la infancia y a la penuria de la condición humana, en uno de las pocas epístolas de las Cartas elaboradas en diálogo directo. Sucede eso en la Carta LIII, de Gazel a Ben-Beley, cuando describe las reflexiones que les induce un niño al que ven jugando con una caña adornada de cintas y papel dorado:

- ¡Feliz edad -exclamé yo-, en que aún no conoce el corazón las penas verdaderas y los falsos gustos de la vida! [...]. Dichoso el hombre si fuese siempre niño.

$-\mathrm{Te}$ equivocas -me dijo Nuño. [...]. Créeme Gazel, la miseria humana se proporciona a la edad de los hombres: va mudando de especie conforme el cuerpo va pasando por edades, pero el hombre es mísero desde la cuna al sepulcro.

Y con tan pésimos augurios termina esa carta. Demasiado sincero quizá, el austero español, con ribetes aguafiestas, que recuerda el título de una obra de Quevedo: La cuna y la sepultura.

21 El tema central de las Noches lúgubres es la amistad y ya hemos comentado lo decepcionado que se sintió Cadalso de sus amigos con respecto a la enfermedad que padeció en 1771. Amistad sincera es lo que sienten los tres corresponsales de las Cartas marruecas, y no resulta por ello extraño la crítica en forma de burla que se hace de la insustancialidad amistosa, pues a Gazel le sorprende que, después de ser presentado por primera vez en una tertulia, escenario idóneo de Los eruditos a la violeta, por cierto, observa que 
Los que encontré en la calle o en la tertulia a la segunda vez ya eran amigos míos; a la tercera, ya la amistad era antigua; a la cuarta, ya se había olvidado la fecha [en que Gazel había sido introducido en esa tertulia]; y a la quinta, me entraba y salía por todas partes sin que me hablase nadie (Carta XI),

lo que constituye una magnífica muestra de observación costumbrista desde los ojos de un extranjero. Con todo, sin salirnos de la misma carta, manifiesta una clara admiración sobre la libertad en el trato: «Todo esto sin duda es muy bueno, porque contribuye a hacer al hombre cada día más sociable»; y esto anima a Nuño a presentar la otra cara de la moneda en una actitud claramente perspectivística, arropada de una marcada voluntad didáctica en esta ocasión, puesto que:

Sin aprobar la demasiada rigidez del siglo XVI, no puedo tampoco conceder tantas ventajas a la libertad moderna. ¿Cuentas por nada la molestia que sufre el que quiere por ejemplo pasearse solo una tarde por distraerse de algún sentimiento o para reflexionar sobre algo que le importe? Conveniencia que lograría en lo antiguo sólo con pasarse de largo sin hablar a los amigos; y mediante esta franqueza que alabas, se halla rodeado de importunos que le asaltan con mil insulseces sobre el tiempo que hace, los coches que hay en el paseo, color de la bata de tal dama, gusto de librea de tal señor, y otras semejantes [...] Piénsalo, reflexiónalo y lo verás.

La severidad del español, frente a la fascinación del trato occidental en el joven marroquí, todo ello en un ambiente de franqueza, cordialidad y aceptación de la diferencia, pues Nuño se dirige a Ben-Beley en estos términos:

Según las noticias que Gazel me ha dado de ti, sé que eres un hombre de bien que vives en África, y según las que te habrá dado él de mí, sabrás que soy un hombre de bien que vivo en Europa. No creo que necesite más requisito para que formemos mutuamente un buen concepto el uno del otro. Nos estimamos sin conocernos; por poco que nos tratáramos, seríamos amigos (Carta XLII),

toda vez que las fronteras culturales, religiosas, políticas y geográficas se superan cuando el norte personal es el bien, o cuando la frontera se ofrece como un elemento integrador, como un desafío personal para ampliar nuestro espíritu por otras regiones, físicas e intelectuales, y no como una impostura separadora. Fronteras para sumar y no para dividir, es lo que defiende Cadalso en su obra, que continúa la anterior carta de Nuño a Ben-Beley de esta manera: «El trato de este joven y el conocimiento de que tú le has dado crianza me impelen a dejar Europa y pasar a África, donde resides.» Y es que lo que el patricio español pretende es recuperar la naturalidad frente al artificio:

[...] quisiera que nos viniesen de África unas pocas docenas de ayos como tú para encargarse de la educación de nuestros jóvenes, en lugar de los ayos europeos, que descuidan mucho la dirección de los corazones de sus alumnos por llenar sus cabezas de noticias de blasón, cumplidos franceses, vanidad española, arias italianas y oros renglones;

sencillez frente a sofistificación estéril, por lo tanto, autenticidad frente a adulteración, que se nos antoja no demasiado distante de las tesis esenciales de Rousseau.

23 Por fin, la fórmula que elige Nuño para despedirse de Ben-Beley en esa carta no puede ser más elocuente de la argumentación que he mantenido en el párrafo anterior:

El Ser Supremo, que nosotros llamamos Dios y vosotros Alá, y es quien hizo África, Europa, América y Asia, te guarde los años y con las felicidades que deseo, a ti y a todos los americanos, africanos, asiáticos y europeos.

24 Y nos queda como el «regustillo» de haber asistido a una nueva contradicción cadalsiana, puesto que al marcado pesimismo de la Carta LIII, que citamos más arriba, y que recuerda a Francisco de Quevedo, se opone este deseo de felicidad. 

existentes: la frontera política y la frontera cultural, la frontera geográfica, la frontera lingüística, la frontera religiosa entre España y Marruecos, pero existe aún otra posibilidad de perspectivismo y, por ello mismo de frontera, que en este caso no sería creación del autor gaditano, sino recreación o reacción ante una frontera ya existente, puesto que, como hemos señalado, las cartas persas, turcas o chinas están en la mente de nuestro escritor a la hora de redactar sus marruecas, pero es realmente la primera de ellas, es decir, la LXVIII de las Cartas persianas, de Montesquieu, la que espolea a Cadalso.

Observamos así que Montesquieu afirma en su epístola, refiriéndose a la cultura española que «El único libro bueno que tienen es el que ridiculiza a todos los otros»" lo que constituye una enorme injusticia contra la riquísima nómina de autores y títulos de nuestra literatura previa a Montesquieu, y una lectura bastante pobre del Quijote, y por eso provoca el comentario de Cadalso, en carta de Gazel a Ben-Beley, para que, toda vez que esa reflexión la realiza un extranjero, ficticio, pero extranjero, el aserto adquiera mayor autoridad: «En esta nación tienen un libro muy aplaudido por todas las demás» (Carta LXI). En otra carta, Gazel observa que, con respecto al bullicio y descompostura de la juventud, que le parece odioso: «Del mismo dictamen es mi amigo Nuño, no obstante lo quejoso que está de que los franceses no sean igualmente imparciales cuando hablan de los españoles» (Carta XXIX). Cuando se dispone a hablar de España, manifiesta Gazel que

[...] no será tanta mi imprudencia que me ponga a hablar de lo que no entiendo, como lo sería decirte muchas cosas de un reino que hasta ahora es enigma para mí, aunque me sería esto muy fácil: sólo con notar cuatro o cinco costumbres extrañas, cuyo origen no me tomaría el trabajo de indagar, ponerlas en estilo suelto y jocoso, añadir algunas reflexiones satíricas, y soltar la pluma con la misma ligereza que la tomé, completaría mi obra, como otros muchos lo han hecho (Carta I),

debajo de lo que no es aventurado adivinar una velada alusión a Montesquieu, quien en la persiana LXXVIII, entre otras muchas invectivas, que sería prolijo enumerar, afirma que

[...] es preciso saber que cuando un hombre tiene cierto mérito en España, como el de poder añadir a las calidades que llevo dichas la de ser dueño de una espada larga o de haber aprendido de su padre el arte de hacer rabiar disonante una guitarra, ya no trabaja más,

que no deja de ser un estereotipo bastante ofensivo. Hasta tal punto parece Cadalso indignado con Montesquieu que el profesor Manuel Camarero en su edición de las Cartas recuerda que en la que preparó Eugenio de Ochoa, para la Biblioteca de Autores Españoles, publicada en 1850, decía que nuestro autor «se propuso pintar las costumbres de su tiempo y rebatir de paso algunos de los groseros errores en que incurrió el célebre Montesquieu al tratar de las cosas de España» ${ }^{10}$. Con todo, Cadalso no renuncia a uno de sus recursos retóricos preferidos, la ironía, que es lo que utiliza en la más evidente alusión a la obra del francés, quien al principio de la tantas veces mencionada Carta LXXVIII afirma que «La gravedad es el carácter resplandeciente de estas dos naciones. Esta gravedad se muestra principalmente de dos modos: en los anteojos y en los bigotes»; e incluye en ello a los portugueses, lo que inspira a Cadalso uno de los pasajes más humorísticos de la obra que nos ocupa, pues ante la llegada de un barco francés al puerto de Cartagena, y comoquiera que los franceses querían comportarse en España como los españoles:

Decir cuál fue el apuro de toda la oficialidad para hallar tantos pares de anteojos cuantas narices había, es inexplicable. [...]. Dos o tres compañías de soldados de galeras, que componían aquella guarnición, habían acudido con el pueblo [a presenciar el espectáculo de ver a todos los franceses cargados de gafas]; y como 
aquella especie de tropa anfibia se componía de la gente más desalmada de España, no pudieron detenerse de la risa. (Carta XLVII) una persona ataviada con ropa del desierto, que habla una lengua oriental, que pertenece al séquito de un embajador, como veremos más adelante, compuesto, entre otros enseres, por camellos, y que pertenece a la religión musulmana, todo ello, aunque no le separa de Europa nada más que el Estrecho de Gibraltar, es por algo. Lo que Cadalso busca, evidentemente, es un juego de perspectivas, como hemos reiterado en este ensayo, pero también busca una apariencia de imparcialidad para sus opiniones, pues una persona tan distinta, aunque tan cercana, como Gazel, permite al escritor opinar, alabar virtudes o denunciar vicios utilizando una voz que en teoría no es la suya, lo que de ese modo le permite arropar sus criterios bajo un halo de objetividad, para que una «mirada, desconocedora de lo europeo, pueda enjuiciarlo ante el lector de una manera crítica y objetiva», según ha destacado el profesor Baquero Goyanes ${ }^{12}$.

Así, Gazel reflexiona sobre algo tan hispano como los toros («te diré que ya no me parecen extrañas las mortandades que sus historias dicen de abuelos nuestros en la batalla de Clavijo, Salado, Navas y otras, si las excitaron hombres ajenos a todo lujo moderno, austeros en sus costumbres y que pagan dinero por ver derramar sangre, teniendo esto por diversión dignísima de los primeros nobles», Carta LXXII). Gazel es el destinatario de la carta de una joven de veinticuatro años, seis veces viuda, después de otros tantos matrimonios concertados por los padres: «aunque he oído muchas cosas que espantan de lo poco favorables que nos son las leyes mahometanas -dice la joven-, no hallo distinción alguna entre ser esclava de un marido o de un padre» (Carta LXXV); lo que permite esbozar un tema que será luego desarrollado en la escena por Leandro Fernández 
de Moratín en El sí de las niñas. Cadalso, como vemos, recurre al contraste entre las leyes no escritas en el siglo xviII europeo, con las sí escritas, aunque medievales, mahometanas, para sostener la idea de la atrocidad de ambas situaciones. Gazel medita en carta a Nuño sobre la materialidad de las infraestructuras ( «Como los caminos son tan malos en la mayor parte de las provincias de tu país, no es de extrañar que se rompan con frecuencia los carruajes, se despeñen las mulas y los viajantes perdan las jornadas», Carta LXIX), tanto como de la inmaterialidad de las virtudes en carta a Ben-Beley («es cosa fuerte que los malos abusen de la paciencia y virtud de los buenos. No me parece ésa menor villanía que la del ladrón que roba y asesina al pasajero que halla dormido e indefenso en un bosque», Carta LXV). Gazel critica el afán de apariencia nominal, es decir la obsesión por los títulos nobiliarios, con perjuicio de las industrias útiles: «procurando todos con increíble anhelo colocarse en la clase de los nobles, menoscabando a la república en lo que producirían si trabajaran» (Carta XXIV); sin embargo, «Pedro Fernández siempre será Pedro Fernández» (Carta XXV), en afirmación de Nuño. Gazel ironiza sobre la frivolidad cuando reproduce la conversación en una tertulia, donde unos jóvenes se desgarran en lamentos apocalípticos, porque: «¿Creerás, Gazel, que en todo Madrid no se ha hallado cinta de este color, por más que se ha buscado» (Carta LVI). Gazel, en fin, entre una lista inagotable de ejemplos, opina sobre su propio país y de ese modo ilustra la imagen cadalsiana de Marruecos: «En Marruecos no tenemos idea de lo que por acá se llama nobleza hereditaria» (Carta XII), lo que no desagradaba en exceso al escritor de Cádiz; «La poligamia entre nosotros está no sólo autorizada por el gobierno, sino aprobada expresamente por la religión»; donde puede o no haber censura moral, pero en todo caso no hay hipocresía, siendo así que en España conoce Gazel un donjuán que se jacta de esta manera:

Pues, amigo, dijo el mozo, yo sin ser moro ni tener serrallo, ni aguantar los quebraderos de cabeza que acarrea el gobierno de tantas hembras, puedo jurarte que entre las que me llevo de asalto, las que desean capitular, y las que se me entregan sin aguantar sitio, salgo a otras tantas por día como tú tienes por toda tu vida entera y verdadera (Carta $\mathrm{X}$ );

«En el imperio de Marruecos todos somos igualmente despreciables en el concepto del emperador y despreciados en el de la plebe [...]; pero en Europa son varias las clases de vasallos en el dominio de cada monarca» (Carta VII), algo que no resulta muy halagüeño ni en uno ni en otro caso, pero al menos en Marruecos no se ha enquistado un sistema rígido de clases. No es en eso, evidentemente, donde debe buscarse la integración transfronteriza, sino en la sensatez de los postulados, como dice Ben-Beley a Nuño, toda vez que: «somos tales los dos que merecemos mutuamente tener un perfecto conocimiento el uno del otro. Alá te guarde» (Carta LXII).

\section{Verosimilitud}

Cadalso recrea el personaje de Gazel y lo moldea con arreglo a su idea de la sociedad, pero para que ese juego de perspectivas funcione la verosimilitud es condición sine qua non, de otro modo, todo el edificio se desbarata. Consciente de ello, sin duda, Cadalso buscó esa verosimilitud desde el mismísimo inicio de las Cartas marruecas, puesto que en 1766 llegó a España un embajador del emperador de Marruecos, Sidi Hamet Al Ghazzali, a quien la Gaceta de Madrid llamaba El Gazel. Buena prueba de la curiosidad que este viaje despertó entre los españoles son los grabados realizados por los pintores Manuel Salvador Carmona y Antonio González Velázquez ${ }^{13}$, siendo así que en la obra de Cadalso, su Gazel es 
un miembro del séquito del embajador, que logra quedarse en España: «He logrado quedarme en España después del regreso de nuestro embajador» (Carta I), son las primeras palabras del texto cadalsiano, por lo que el vínculo entre la ficción y la realidad queda plenamente establecido, o al menos de manera creíble. Una vez establecido lo anterior, el texto de Cadalso está plagado de detalles que apuntalan dicha impresión de verosimilitud: no basta con que la observación de una persona de otro país sea imparcial, además ha de parecer creíble.

Así, por ejemplo, Nuño pide a Gazel un relato certero de lo que éste observa en sus viajes por España: «Desde tu llegada a Bilbao no he tenido carta tuya: la espero con impaciencia, para ver qué concepto formas de esos pueblos en nada parecido a otro alguno» (Carta LXVII); por lo que el marroquí, cuando lo escribe lo hace sobre lo que conoce, desde su punto de vista de viajero foráneo. El pensamiento, pues, de Gazel se conforma con arreglo a aquello de lo que es testigo: «Por la última tuya [de Ben-Beley] veo cuán extraña te ha parecido la diversidad de provincias que componen esta monarquía. Después de haberlas visitado, hallo muy verdadero el informe que me había dado Nuño» (Carta XXVI). Lo mismo sucede en otros momentos de la obra, puesto que Gazel se toma la molestia de recorrer Francia antes de opinar sobre ella, algo que evidentemente Montesquieu no hizo con respecto a España. Dice así el joven marroquí en carta a su maestro Ben-Beley:

Cuando hice el primer viaje por Europa te di noticia de un país que llaman Francia, que está más allá de los montes Pirineos. Desde Inglaterra me fue muy fácil y corto el tránsito. Registré las provincias septentrionales; llegué a su capital, [...]. Ahora he visto la parte meridional de ella, saliendo de España por Cataluña y entrando por Guipúzcoa, inclinándome hasta León por un lado y Burdeos (Carta XXIX);

donde León, evidentemente, es la ciudad francesa de Lyon. Es la de Gazel una opinión desprejuiciada, es un conocimiento sobre el terreno: ésa es precisamente la ficción que quiere construir Cadalso en sus Cartas marruecas: reflexiones sin arbitrariedades, criterios creíbles. Tras lo anterior se extiende Gazel en una serie de consideraciones acerca de por qué los franceses son despreciados en el siglo XVIII, de la misma manera que los españoles lo fueron en el xvII («sin duda porque uno y otro siglo han sido precedidos de las eras gloriosas respectivas de cada nación»), pero a nosotros nos interesa ahora constatar cómo Cadalso cimenta su afán de verosimilitud. El propio autor sitúa esa cuestión en la «Introducción» a su obra: «me pareció que podría trabajarse sobre este asunto con suceso, introduciendo algún viajero venido de lejanas tierras, o de tierras muy diferentes de las nuestras en costumbres y uso»; donde «suceso» siginifica 'éxito' en este caso. Y para lograr una imagen de imparcialidad, a renglón seguido recurre a la técnica del apócrifo:

La suerte quiso que, por muerte de un conocido mío, cayese en mis manos un manuscrito cuyo título es: Cartas escritas por un moro llamado Gazel Ben-Aly, a BenBeley, amigo suyo, sobre los usos y costumbres de los españoles antiguos y modernos, con algunas respuestas de Ben-Beley y otras cartas relativas a éstas. se oculta detrás de un supuesto texto encontrado por azar, por lo que se acentúa la impresión de realidad del libro.

Por fin, si la Carta I se inicia asentando la verosimilitud de la presencia de Gazel en nuestro país y se justifica su posición para opinar, la obra también se cierra de manera verosímil:

En la última carta de Ben-Beley que me acabas de remitir, según tu escrupulosa costumbre de no abrir las que vienen selladas, me hallo con noticias que me llaman 
con toda puntualidad a la corte de mi patria. Mi familia acaba de renovar con otra ciertas disensiones antiguas, en las que debo tomar partido (Carta XC de Gazel a Nuño),

por lo que el marroquí debe regresar para terciar en esas disensiones, "muy contra mi genio natural".

\section{NOTAS}

1. Juan Luis Alborg, Historia de la literatura española. Siglo XVIII, Madrid, Gredos, 1975, p. 714.

2. Mariano Baquero Goyanes, Perspectivismo y contraste (de Cadalso a Pérez de Ayala), Madrid, Gredos, 1963, pp. 12-13.

3. J. L. Alborg, Historia de la literatura española. Siglo XVIII, op. cit., p. 742.

4. Nigel Glendinning y Lucien Dupuis, «Prólogo» a su edición de las Cartas marruecas, Londres, Tamesis Books, 1971, p. xxxviI.

5. Platón, El banquete o Del amor en Diálogos, Madrid, Espasa Calpe, 1999, p. 258, edición a cargo de Carlos García Gual. Sobre los tres niveles de eternidad en esta obra de Platón, véase también Rodríguez Barranco, Francisco Javier, La vida de una imagen, Málaga, Servicio de Publicaciones de la Universidad, 2005, pp. 363-368.

6. M. Baquero Goyanes, Perspectivismo y contraste (de Cadalso a Pérez de Ayala), op. cit., p. 18.

7. Íbidem, p. 18.

8. N. Glendinning y L. Dupuis, «Prólogo» a su edición de las Cartas marruecas, op. cit., p. XXXVII.

9. Véase la Carta LXXVIII de Montesquieu en el «Documento I» de los recogidos por Manuel Camarero para la edición ya citada de las Cartas marruecas, pp. 259-261.

10. Véase en José Cadalso, Cartas marruecas, op. cit., p. 270.

11. Véase en J. L. Alborg, Historia de la literatura española. Siglo XVIII, op. cit., pp. 739-751.

12. M. Baquero Goyanes, Perspectivismo y contraste (de Cadalso a Pérez de Ayala), op. cit., p. 16.

13. Para más información sobre el interés despertado en Madrid por la visita de El Gazel, véanse las páginas 26-27 de la «Introducción» de Manuel Camarero en su edición de las Cartas marruecas, que es la que estoy siguiendo en mi estudio.

\section{RESÚMENES}

¿Para qué sirve la literatura? Y acaso pudiéramos responder con otra pregunta, al galaico modo: ¿Hemos de buscar una función a la literatura? Para contestar a lo cual hay casi tantas posibilidades como escritores, pero es evidente que dentro de la perspectiva positivista que caracterizó al siglo XVIII, a la literatura se le buscó un fin de utilidad pública. No de otro modo hemos de entender las Cartas marruecas, terminadas en 1774 por José Cadalso, que tomó como referentes las Cartas Persianas, Turcas o Chinas, de allende los Pirineos, escritas las primeras por 
Montesquieu en 1721; corresponden quizá las segundas a Cartas de un turco en París (1731), atribuidas a Poullain de Saint-Foix; y las chinescas quizá sean las de Jean-Baptiste d'Argens (1739-1740), o las de Oliver Goldsmith (1760). Lo que verdaderamente interesa a los fines de este ensayo es que no se trata de un viajero extranjero opinando sobre los países que recorre, como hicieron los viajeros románticos, por ejemplo, sino que los autores recién mencionados se valen de unas fronteras políticas y culturales para crear la ficción de un ciudadano oriental opinando sobre un país europeo. Con otras palabras, estamos asistiendo a una frontera inventada o a la creación de una frontera literaria, puesto que detrás de estos marroquís, persas, turcos o chinos se halla la voz del autor. Todo eso sin olvidar que ya de por sí el epistolar es un género fronterizo entre la narrativa y el ensayo.

What is the use of Literature? Perhaps we could answer that question with another one: Have we the need of looking for an use for Literature? And there are so many answers to that question as writers exist, but it is obvious that within the common positivist perspective of the Eighteenth Century, it was searched an aim of public utility, that is the way we should understand Moroccan Letters, finished in 1774 by José Cadalso, who took as references the Persian Letters, Turkish and Chinese, beyond the Pyrenees, written the first ones by Montesquieu in 1721; the second ones perhaps belong to Letters of a Turkish in Paris (1731), attributed to Poullain de Saint-Foix; and it is possible that the Chinese are the ones by Jean-Baptiste d'Argens (1739-1740), or the ones by Oliver Goldsmith (1760). What is really relevant for us is that the plot in those texts is not a foreigner traveler thinking of the countries he visits, as the Romantic travelers did, for instance, but the just mentioned authors use some political and cultural borders to create the fiction of an Eastern citizen thinking of an European country. In other words, we are attending to an invented border, what means the creation of a literary border, due to the fact that the author's voice is behind those Moroccan, Persian, Turkish or Chines people. Furthermore, we should not forget about the fact that the epistolary genre is itself a frontier genre between narrative and essay.

\section{ÍNDICE}

Palabras claves: frontera, literatura, siglo XVIII, Cadalso

Keywords: frontier, literature, 18th century, Cadalso

\section{AUTOR}

\section{FRANCISCO JAVIER RODRÍGUEZ BARRANCO}

Universidad de Alcalá, ACISAL 